\title{
Discussion on the role of teachers in PBL teaching mode
}

\author{
Haiyan LIU 1, a \\ ${ }^{1}$ Information Technology Institute of Jilin Agricultural University, Changchun, CHINA \\ ahaiyan_49@sohu.com
}

Keywords: Problem Based Learning; Teaching Mode; Teachers Staff

\begin{abstract}
Problem Based Learning (PBL) model have also adopted the teaching model for teaching reform and made some achievements in recent years. The teaching effect is not as ideal as that of researchers. Problems, students and teachers are the three basic elements of Problem Based Learning. Teachers are the key to ensure the learning effect. Teachers participate in the preparation of the PBL problem and design learning form. In PBL process, teachers put forward the problem that can be challenging to promote students to learn important concepts and principles. Teachers need accurate evaluation of student PBL learning. Teachers' cooperation and teaching enthusiasm can influence the teaching effect of PBL. The implementation of PBL is a challenge for teachers. PBL good teaching effect need to train the teacher, change the teacher's understanding and improve the related ability.
\end{abstract}

\section{Introduction}

Problem-based Learning is a new type of teaching mode with the influence of constructivism. A large number of domestic education introduced PBL teaching method in different areas and different stages of learning, such as medicine, law, physics, economics, architecture, management science and so on. It is found that PBL teaching can improve students' self learning ability, cooperation ability, expression ability, understanding ability and problem solving ability, but the teaching effect is not as ideal as foreign researchers have said[1,2].

Problems, students and teachers are the three basic elements of the problem - based learning. The students accepted the teacher centered teaching mode, the lack of independent thinking and independent learning ability and habit. Therefore, it is very difficult for college freshmen to quickly accept PBL teaching. The realization of PBL is a high level of knowledge integration among multiple subjects. The case or problem of thinking about the value of the teacher's design is based on the thinking and psychological characteristics of the students. The Teachers need design A case of thinking or problem According to different students' thinking and psychological characteristics. Teachers need to improve their knowledge structure, culture of keen survey and analysis, comprehensive ability and strong direction and information support capability, which is a great change of educational ideas and operation ability and increase the challenge [3]. Teachers are the key to achieve a good teaching effect of PBL.

\section{Design of the Problem}

The teachers need to ask questions and create situations for learners. The teacher asked the students to learn and acquire skills in the process of solving the problem, and finally put forward the solution to the problem based on the problem of the learning process. Designing an effective problem is not easy. At present, there are no ready-made PBL teaching materials in all subjects. At present, there 
are no ready-made PBL teaching materials in all subjects. Most press is written in a single discipline system, which requires $\mathrm{PBL}$ teaching experience to prepare some of the teachers to discuss the issue of PBL.

Under normal circumstances, the design issues should follow the following principles. First of all, the problem is difficult to moderate. The same theme can be designed according to the age characteristics and cognitive level of students from different angles. A complex or simple problem can restrain the active master of the learner. It has a negative impact on the process of exploring resources and solving problems. Second, the problem should be in the real world to meet some of the complex issues as the core. Such a problem will be more attractive to students, which can prompt students to have greater interest and initiative in solving the problem. Third, according to the curriculum objectives to determine the main concepts and principles of the curriculum, the problem of PBL design should be based on the curriculum objectives. Teachers around a theme of different levels of difficulty of the design of the problem, students can put forward problems from different sides.

\section{The Design of Learning Style}

Group cooperation to solve the problem is an important feature of PBL. In this process, teachers need to prepare the appropriate learning environment and provide the students with some resources to solve the problem. An ideal learning environment is suitable for 8-10 people learn. Students can sit around and discuss. The problem based learning curriculum is all open. Teachers need to be open to learning objectives, learning resources and assessment methods.

Teachers to develop the functions of the PBL team to develop outlines and implementation procedures. There will be "strong", "weak", or "lazy" members in each group. Through the feedback of the students' learning behavior, the teachers can adjust the learning process by the students themselves.

\section{Teachers PBL Guidance Skills}

The teacher is the promoters of PBL Teaching. In order to promote students' learning, teachers need to put forward to be able to think about the process of students, application demonstration, questioning and encouragement and other activities to help students find the solution to the problem. This means that teachers provide support to students. With the improvement of the ability of students, students can become independent learners. PBL teachers need to pay attention to whether students master the knowledge and help students become autonomous learners to stimulate their learning fun and develop their lifelong learning skills. The team would neglect other aspects when group discussion too entangled in a point. There are too many speeches which hinders the study of other members of the group in the group. If the opinions of the weak in the group are ignored by other members, the teacher provides the appropriate guidance. The ideal director should be both a subject and a specialist. A little less than a point of guidance is not a subject experts, should also be good at guiding. The worst director may be a subject, but he is not a guide. A PBL's mentor should have two basic skills that is discipline and guidance skills. The instructor needs to learn to master the PBL guidance skills, and to develop in the PBL teaching process to be adept. Therefore, we must first train the teachers to guide the skills before PBL teaching. 


\section{Design of learning evaluation}

Teaching and evaluation are all for the students. Evaluation of PBL learning effects of students usually use the combination of two evaluations, an evaluation is to solve the problem before the formation of learning, and another evaluation is the results of PBL activities in the late report forms. The first evaluation of the purpose is to let the teacher a better understanding of the students' personality tendency, thinking ability and learning situation. It can provide timely feedback to teachers and students in order to help them adjust their teaching in time and to achieve the best teaching condition. The purpose of the second evaluation is to provide reference information for teaching plan and teaching plan, which is to provide students with an achievement orientation and motivation of students. The evaluation form of PBL curriculum should be able to encourage students to learn the way that PBL students should be able to learn. PBL courses are not likely to be successful if they only require students to memorize the facts. Problem learning is open to the PBL evaluation method cannot be unified. Evaluation is a combination of a variety of evaluation methods, such as the design of written examination (written), the practice test (operation), oral presentation and written reports, etc.

\section{Teachers' Cooperation}

Problem based learning is often used in the form of cooperative learning, through the interaction between the individual to achieve the purpose of solving the problem. Teacher collaboration problem based learning (PBL) is a common, it can play to their respective advantages in teachers, complement each other, learn from each other. The problem to be solved in PBL is varied. Generally speaking, it includes two aspects, life and social problems. Teachers prepare the subject, method and learning resources. Currently China has skilled PBL coaching skills teacher also few, new teachers in the process of learning such as confused or encounter difficult problem, need through a variety of interactive communication ways, from experienced teachers guide there get answers and guidance.

\section{Teaching Ideas and Teaching Enthusiasm}

PBL not only requires teachers to master knowledge, but also requires teachers to have a profound understanding of the inherent logic of knowledge to solve practical problems. This is a kind of teaching mode which requires a high demand for teachers. In the process of PBL teaching, the teacher is enthusiastic, keen, coordination, and can tolerate the students' mistakes. This is a kind of teaching mode which requires a high demand for teachers. In the process of PBL teaching, teachers need to prepare the case, the establishment of the website, the feedback of students, teachers in teaching time to pay more time and energy. PBL teaching is a teaching model which has higher requirements for teachers. PBL teaching needs the support of policies and funds to carry out a large area of PBL teaching.

\section{Summary}

From the above discussion, we can see that the implementation of PBL is a challenge to teachers. In order to truly practice the concept and purpose of PBL, we need to train teachers, change the teacher's awareness of PBL and related ability. At this stage in order to improve the teaching effect of PBL, the university or college level should play a key role to provide the corresponding platform for teachers [4]. 
The problem based learning is different from the traditional teaching. There are great differences between the traditional teaching methods such as teaching plan, evaluation method, goal setting, the use of information and learning support. PBL teaching is helpful to improve students' ability to solve problems, and it is a kind of active teaching method. Teachers should take the initiative to learn the way of learning and constantly improve their teaching ability.

\section{Acknowledgement}

Key teaching and research topics of Jilin Agricultural University, The Application of PBL Teaching Model in the Construction of Innovative Talents Training System, 2013xjzd058

\section{References}

[1] He Jinsen, Li Yi, Liu Shimin, et al. Experience in Application of PBL Teaching Method in the Clinical Teaching of Acupuncture[J]. Journal of Acupuncture \& Tuina Science, 2007, 5(6):321-323.

[2] Song X Q, Shen C L, Sheng X U. Exploration and Practice of Project and the PBL Teaching Method in The Teaching of Single Chip Microcomputer[J]. Computer Knowledge \& Technology, 2015, 78(1):173-190.

[3] Lavy V. Using performance-based pay to improve the quality of teachers.[J]. Future of Children, 2007, 17(1):87-109.

[4] Korin T L. Problem-based learning faculty development: a comprehensive approach [J]. Medical Education, 2007, 41(11):1086-7. 